Dialectologia. Special issue, IX (2021), 311-339.

ISSN: 2013-2247

Received 1 March 2021.

Accepted 15 March 2021.

\title{
EVOLUCIÓN Y DISTRIBUCIÓN DE /s/ EN CODA SILÁBICA EN ESPAÑOL EN EL ATLAS LINGÜÍSTICO DE LA PENÍNSULA IBÉRICA ${ }^{1}$
}

\author{
Patricia RIBAS MARÍ \\ Universidad Autónoma de Madrid * \\ patricia.ribas@uam.es
}

Resumen

Este trabajo estudia el proceso evolutivo de la glotalización y pérdida de /s/ en posición implosiva en el español peninsular desde una perspectiva geolingüística a partir de los datos del Atlas Lingüístico de la Península Ibérica $(A L P I)$. El cartografiado de los datos permite observar la extensión geográfica de este fenómeno y las diferentes etapas evolutivas que presenta. Los resultados revelan el comportamiento variable de $-/ \mathrm{s} /$ según la posición en la cadena fónica, el contexto fonético y el contexto fonético-sintáctico.

\section{Palabras clave}

/s/ en coda silábica, cambio fonético, fonética sintáctica, geolingüística

\section{EVOLUTION AND DISTRIBUTION OF FINAL/S/ IN SPANISH IN THE ATLAS LINGÜÍSTICO DE LA} PENÍNSULA IBÉRICA

Abstract

Based on the data from the Atlas Lingüístico de la Península Ibérica (ALPI) this paper studies the evolutionary process of final /s/ in Peninsular Spanish from a geolinguistic point of view. The mapping of

\footnotetext{
${ }^{1}$ Este trabajo ha sido realizado en el marco del proyecto PGC2018-095077-B-C42, financiado por el Ministerio de Ciencia, Innovación y Universidades, dirigido por Inés Fernández-Ordóñez y Ana Serradilla Castaño.

* Departamento de Filología Española, Módulo IV, Facultad de Filosofía y Letras, Universidad Autónoma de Madrid, Campus de Cantoblanco, 28049 Madrid.
} 
the data displays the geographic extension of the phenomena of loss and aspiration of the sibilant -/s/ and its different evolutive phases. The results reveal the changing behaviour of the $-/ \mathrm{s} /$ depending on its position in the sound sequence, on phonetic context and on syntactic phonetics context.

\section{Keywords}

final /s/, sound change, syntactic phonetics, geolinguistics

\section{Introducción}

La glotalización y pérdida de la /s/ implosiva es uno de los fenómenos fonéticos más estudiados del español por la posibilidad que presenta de modificar el sistema fonológico de la lengua. Este fenómeno es uno de los rasgos que permiten separar lingüísticamente el norte y el sur peninsulares, pues la aspiración y pérdida de /s/ en coda silábica se considera una característica meridional que se localiza en Andalucía, Murcia, Extremadura, Castilla-La Mancha, y también en Canarias. A estos territorios de debilitamiento de la sibilante algunos estudios añaden las zonas del sur de Salamanca, de Ávila y Alicante (Zamora Vicente 1967, Catalán 1971) y las capas populares de Madrid (Alarcos 1950, Lapesa 1980, Martín Butragueño 1995, Alvar 1996, Penny 2000, Moreno Fernández 2004, Paredes García 2006 o Molina Martos 2015). Además, Navarro Tomás (1975) ya apuntó que /s/ y / $\theta$ / en posición implosiva presentaban cierto grado de reducción en el occidente de Castilla y León.

También en el norte peninsular se han detectado ejemplos de aspiración, especialmente en Cantabria, como recogen los estudios de la localidad de Tudanca (Penny 1978, 1991), y en una zona que comprendería algunos enclaves de los antiguos territorios asturiano-leoneses: el occidente de Cantabria, el oriente de Asturias y una pequeña zona de León (Penny 1991). ${ }^{2}$

El origen geográfico del fenómeno de debilitamiento de $-/ \mathrm{s} /$ se ha situado en el occidente de Andalucía y, en concreto, en Sevilla (Catalán 1971, Fernández-Sevilla 1980). Desde este epicentro se habría extendido hacia otras áreas peninsulares en

\footnotetext{
${ }^{2}$ Estas zonas septentrionales en las que se documenta la aspiración de $-/ \mathrm{s} /$ coinciden con las zonas en las que se aspira /f/ inicial. En principio, dejamos fuera esa zona de este estudio y, por lo tanto, aparece en blanco en los mapas infra.
} 
forma de círculos concéntricos, como puede deducirse de la interpretación dinámica de los datos del análisis de Catalán (1971). Pero también hay estudios que sugieren que el fenómeno pudo ser general a todo el territorio castellano (cfr. Frago 1983, Pascual 1998), ya desde finales de la Edad Media, y que solo el influjo de la variedad culta y escrita habrían frenado la evolución de la glotalización en el norte peninsular. Sobre esta hipótesis, especialmente a partir del trabajo de Pascual (1998), Ariza (1999) se plantea si los casos de aspiración y pérdida que se documentaban en otras zonas castellanas podrían ser ejemplos de conservación de ese fenómeno medieval o si se trataba de innovaciones más recientes, y propone que la disparidad de los resultados, debidos al contexto fonético, parecían indicar un cambio incipiente, descartando así que los ejemplos fueran restos de un fenómeno general anterior.

En cuanto a la cronología del debilitamiento de $-/ \mathrm{s} /$, el origen del fenómeno suele datarse de forma mayoritaria en el siglo $\mathrm{XV}$, aunque no hay consenso entre los lingüistas que lo han estudiado. Así lo propone Fernández-Sevilla (1980), quien incluso señala que podría ser anterior, y a finales de este siglo lo sitúan los estudios de Lapesa (1980), Pascual (1998) o Penny (2000). Ariza (1999) equipara la antigüedad del debilitamiento de /s/ en coda silábica a la aspiración de /f/ inicial y apunta que en formas como nosotros y vosotros la aspiración ya se habría dado a finales del XV. Por su parte, Sánchez Romo (2014) testimonia casos de aspiración y pérdida de la sibilante en documentación del sur de Ávila en la primera mitad del siglo.

Sin embargo, otros autores han propuesto distintas cronologías para el origen de la glotalización. La cuestión estriba fundamentalmente en la interpretación de los ejemplos que se proponen, pues unos autores los consideran casos de aspiración o pérdida de la sibilante y otros autores los catalogan como simples errores cometidos en el proceso de escritura. Frago (1983) documenta ejemplos de elisión ya en el siglo XIV. Y otros, como Torreblanca (1989), señalan que el debilitamiento sería posterior al siglo XV, atendiendo a los rasgos del judeoespañol, donde -/s/ se conserva y solo se palataliza ante velar /sk/ (Lapesa 1980, Lleal 2004), y de las variedades americanas, pues no en todas las zonas de América se documenta la glotalización y su distribución es irregular (Canfield 1981, Penny 2000). Más tarde lo sitúa Salvador (1987), quien 
señala incluso que el desarrollo y la difusión del cambio no se habría producido hasta el siglo XIX.

Además, hay que tener en cuenta que el proceso de aspiración y pérdida no se produce con la misma intensidad en todos los contextos ni ante todos los sonidos. La posición de /s/ en distensión silábica que más favorece el debilitamiento es el margen entre palabras, después la posición interior, la posición final absoluta y, finalmente, el contexto prevocálico (Fernández-Ordóñez 2016: 396). Sin embargo, la pérdida total de la sibilante, que es la etapa final del cambio, se produce con más frecuencia en la posición final absoluta, a pesar de no ser el contexto que primero se ve afectado por el proceso de debilitamiento. Por el contrario, en las dos posiciones en que se origina el cambio, es decir, posiciones donde $-/ \mathrm{s} /$ va seguida de consonante, predomina la aspiración u otras etapas del debilitamiento (Samper Padilla 2011, Fernández-Ordóñez 2016).

Los sonidos que siguen a -/s/ también inciden en el proceso. En la siguiente escala se colocan a la derecha aquellos sonidos que más favorecen el debilitamiento y a la izquierda los que lo favorecen en menor medida: "/r/ > /m, $n, I, f, x, \theta, b, d, g />/ p$, t, k/ > /t/" (Fernández-Ordóñez 2016: 396). Como vemos, las consonantes líquidas y nasales y las fricativas sonoras son las que contribuyen más al debilitamiento, mientras que las oclusivas sordas facilitan el mantenimiento de la sibilante.

Dado el polimorfismo del fenómeno (Catalán 1971), en el proceso de glotalización de la sibilante intervienen varios factores que se superponen: por un lado, la extensión geográfica del fenómeno y la diacronía o las diferentes etapas evolutivas del cambio; por otro, la posición que ocupa -/s/ en la cadena fónica, el contexto fonético que sigue a $-/ \mathrm{s} /$ y el contexto sintáctico en el que se inserta la sibilante.

El propósito de este trabajo es analizar la /s/ en distensión silábica en diferentes contextos fonéticos y sintácticos y determinar la extensión geográfica del debilitamiento a partir de los datos del Atlas Lingüístico de la Península Ibérica (ALPI). El $A L P I$ nos ofrece la posibilidad de estudiar el estado de la evolución de /s/ en coda silábica y su alcance geográfico en el español de principios del siglo XX. 


\section{La /s/ implosiva en el ALPI}

La distribución de /s/ en coda silábica en el $A L P I$ ha sido objeto de estudio en trabajos previos. Navarro Tomás publicó los mapas del comportamiento de las consonantes finales a partir de los datos del atlas, entre los que se incluye el mapa de /s/ (1975: 190). En este mapa Navarro Tomás demarcó las grandes zonas geográficas peninsulares de pronunciación de la sibilante en posición prepausal en la forma árboles: plena -Logroño, Soria, Guadalajara, Cuenca y Albacete-, reducida -Cantabria, Burgos, Palencia, Valladolid, Segovia, Ávila, Madrid, Toledo y Ciudad Real-, palatalizada -para el portugués-y eliminada -Andalucía, Extremadura y Murcia.

Catalán (1971), por su parte, también estudió el proceso evolutivo de -/s/ en el $A L P I$ y definió cuatro sub-áreas geográficas que consideraba como "una proyección en el espacio de cuatro estadios sucesivos de un proceso diacrónico" (1971: 99), que fueron ampliadas a seis por Fernández-Ordóñez (2016). En este sentido, Catalán precisó una geografía interna para la pérdida y aspiración de $-/ \mathrm{s} /$ y $-/ \theta /$ y definió el proceso como lento, pues habrían transcurrido varios siglos desde el comienzo del fenómeno y aún no había llegado a eliminar la -/s/ en todos los contextos, e inestable, por presentar varias posibilidades en una misma localidad o incluso en el idiolecto de un hablante.

Sin embargo, el estudio de Catalán estuvo limitado porque entonces los datos fonéticos del $A L P I$ no habían sido editados por completo y no pudo tener acceso a los materiales de los que disponemos hoy. Así, Catalán solo tuvo en cuenta voces aisladas, ${ }^{3}$ es decir, estudió -/s/ en posición final absoluta y en posición interior, y dejó fuera del análisis el comportamiento de /s/ en contextos de fonética sintáctica, que ha adquirido mayor relevancia en épocas posteriores (cfr. Méndez Dosuna 1987, Samper Padilla 2011)..$^{4}$

\footnotetext{
${ }^{3}$ Las preguntas estudiadas por Catalán (1971) fueron: a) en posición final: árboles, cejas, cuñados, deudas, los domingos, coz, cruz, diez y duz; b) seguidas de consonante: avispa, desbocado, desnudo, castillo, cresta, y guizque.

${ }^{4} \mathrm{Al}$ margen de los datos del $\mathrm{ALPI}$, se han llevado a cabo numerosos estudios sobre la /s/ en posición implosiva en varias zonas: en Ciudad Real y Toledo (García Mouton y Moreno Fernández 1994), Las Palmas (Samper Padilla y Hernández-Cabrera 1995), el sur de Madrid (Martín Butragueño 1995, Molina
} 
Nuestro estudio pretende ampliar el trabajo de Catalán en cuanto a la posición de /s/ en coda, por lo que incluimos el margen entre palabras y la posición prevocálica. De esta forma podremos observar la relevancia de la sintaxis en el cambio fonético. Así, nos interesa comprobar las diferencias del proceso evolutivo de la sibilante según la posición que ocupa en la cadena fónica: final absoluta, final interior y final agrupada por fonética sintáctica (seguida de vocal o seguida de consonante); y también según el sonido consonántico que sigue a -/s/. Para ello, hemos seleccionado 38 preguntas $^{5}$ del cuaderno I del $A L P I$ y hemos cartografiado los datos obtenidos.

Para la extracción de los datos hemos seguido los criterios seguidos para la edición digital del ALPI (García Mouton et al. 2016). Por tanto, no hemos distinguido entre realizaciones plenas y realizaciones relajadas, pues no se contempla tal diferencia en la edición digital. Tampoco hacemos distinción de los tipos de sibilante o de si la aspiración es sorda [h] o sonora [h] puesto que consideramos que por el momento no son cuestiones relevantes en nuestro análisis. Los mapas que presentamos no solo reflejan la pérdida, la aspiración o el mantenimiento de -/s/, sino que muestran también otros resultados fonéticos como el rotacismo, la geminación o la asimilación de la consonante que sigue a la sibilante.

\section{$2.1-/ s /$ prepausal}

La posición final absoluta es la que mayor favorece la pérdida de /s/ en coda. Como puede verse en el Mapa 1, la pérdida alcanza por el occidente el límite septentrional de la provincia de Cáceres y por el oriente la elisión de la sibilante se

Martos 2015), Toledo (Molina Martos 1998), El Hierro (Pérez-Martín 2003), Málaga (Vida 2004), el sur de Ávila (Sánchez Romo 2011) o, entre otras, el sur de Salamanca (Francisco Sánchez 2019).

${ }^{5}$ Los ejemplos del ALPI analizados son los siguientes: a) en posición final absoluta: 244 Domingos; b) en posición interior: 177 Avispa, 83 Cresta, 160 Escopeta, 104 Resbalar, 395 Desde, 212 Rasgar, 304 Mismo, 10 Desnudo, 102 Isla; c) en el margen entre palabras: 382 Ayer salieron los pastores, 260 Mis cuñados y mis primos, 243 Las botellas, 244 Los domingos, 245 Las yemas, 247 Las huertas, 248, Los reyes, 377 Anteanoche vinieron los mozos, 407 Sirvió solo dos semanas, 384 ¿Has barrido ya?, 385 ¿A qué hora has llegado?, 335 Nos verá cuando vengamos, 314 Cada mes cambia de oficio, 396 Cuanto más siegues mejor, 318 Antes que amanezca, 281 Tenemos cada uno diez duros, 411 Lo queréis para vosotros, 315 ¿Cuándo salís de viaje?, 336 ¿Sois parientes del alcalde? y 253 Lo primero es la salud; d) en posición prevocálica: 361 A las hermanas les enviaron unas cartas, 342 Os han engañado, 354 Me pidieron que les ayudase, 357 Tráete los candiles para echarles aceite, 303 Entonces escampó, 337 Tú y yo somos amigos, 304 Vamos ahora mismo, 332 Fuimos a la feria. 
limita a la región de Murcia. Este desarrollo de la evolución de -/s/ parece coincidir con la hipótesis de Catalán (1971) de que el fenómeno surge en Sevilla y desde ahí se extiende hacia el resto del territorio en círculos concéntricos.

Es significativo que en Castilla-La Mancha predomine el mantenimiento de la sibilante y apenas se documenten ejemplos de pérdida o de aspiración. Como veremos en otros contextos fonético-sintácticos, este es el territorio donde confluyen más resultados distintos de $-/ \mathrm{s} / \mathrm{y}$, por lo tanto, es la zona en la que mejor se pueden observar las etapas de este proceso evolutivo con los datos del ALPI.

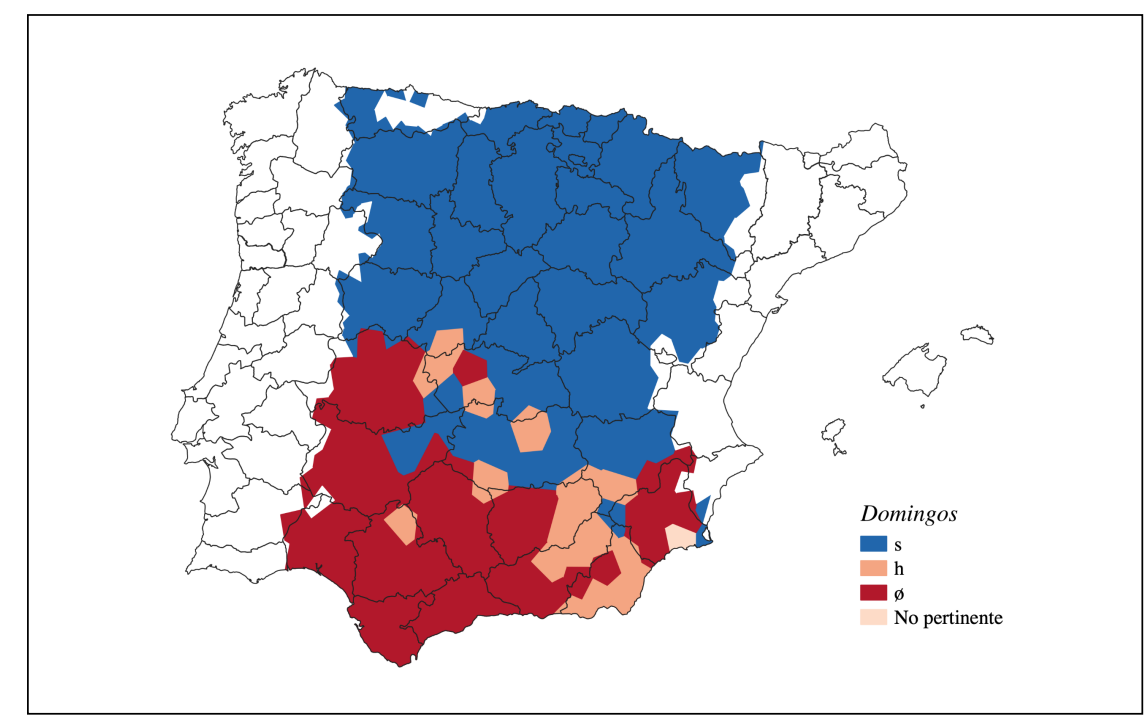

Mapa 1. -/s/ en posición final absoluta.

La fase de aspiración proyectada en el mapa se documenta especialmente en el oriente andaluz y en algunos puntos aislados de las provincias de Ciudad Real, Toledo y Ávila. Cabría esperar que la aspiración estuviera más difundida en Extremadura y Murcia, zonas alejadas del supuesto epicentro, pero, en este contexto, no se diferencian de aquel. Ello, unido a la gran extensión meridional donde se pierde la sibilante, demuestra que, a pesar de que la posición prepausal, como veremos, no es el primer contexto afectado en este cambio fonético, es la posición que más favorece la pérdida total de la sibilante. 


\section{$2.2-/ s /$ interior}

En cuanto a -/s/ en posición interior de palabra, los mapas reflejan las distintas fases del proceso evolutivo según el sonido consonántico que le sigue. Como hemos visto, la nasal alveolar es uno de los sonidos que más favorecen el debilitamiento. Si nos fijamos en el Mapa 2, que proyecta los datos de desnudo, podemos observar cómo la glotalización se extiende por prácticamente la totalidad del espacio meridional peninsular e, incluso, penetra por el occidente en la provincia de Salamanca y de Ávila, en las que solo los enclaves más septentrionales conservan la sibilante. También la aspiración se documenta, de forma más esporádica en el sur de Madrid y en el sur de Cuenca.

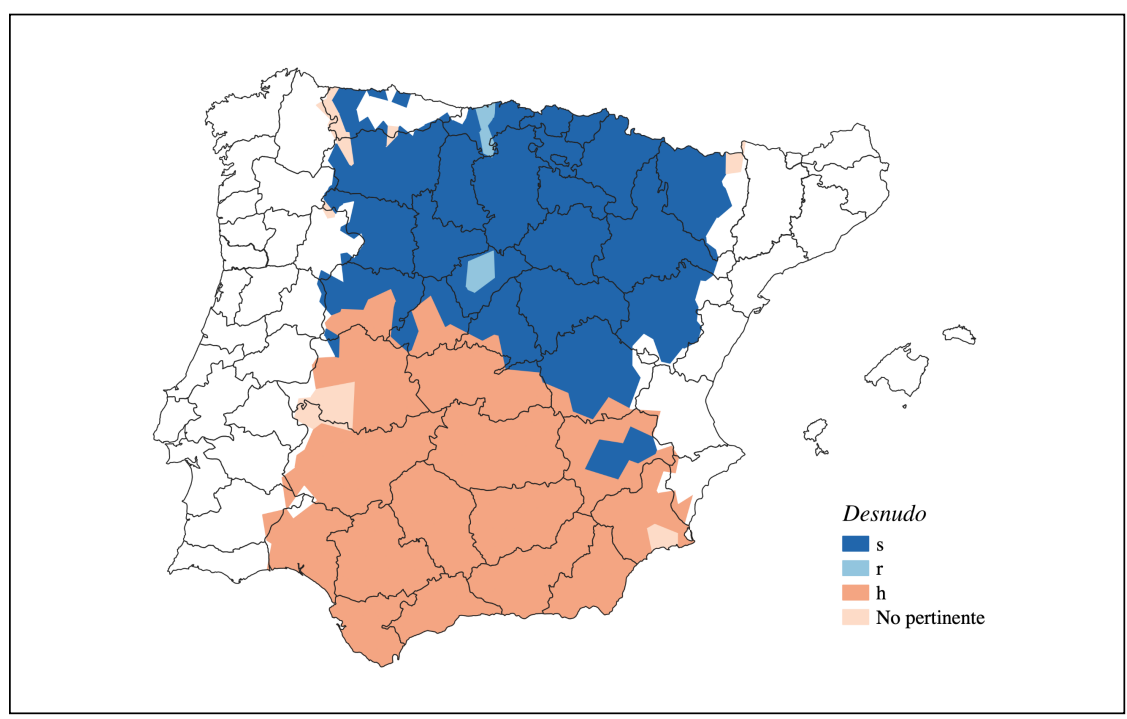

Mapa 2. -/s/ seguida de /n/: desnudo.

El Mapa 3, que recoge los datos de resbalar, muestra resultados bien diferenciados del contexto fonético anterior. En este mapa son cuatro las etapas principales del proceso: pérdida, ensordecimiento, aspiración y mantenimiento. Los casos de pérdida se documentan en el epicentro del fenómeno propuesto por Catalán (1971), Sevilla, y los alrededores, Huelva y Cádiz, pero también en enclaves aislados de León (Pontedo), Madrid (Valdelaguna) y Jaén (Baeza). Los escasos ejemplos de aspiración se sitúan en enclaves del sur de Málaga, Granada y Almería. El resto de la mitad meridional de la Península presenta ensordecimiento en $[\phi]$ como resultado de 
la glotalización. Otros resultados como el rotacismo de -/s/ (Cuantas, Asturias) o la geminación de la consonante bilabial (Higueruela, Albacete) son casos aislados y esporádicos.

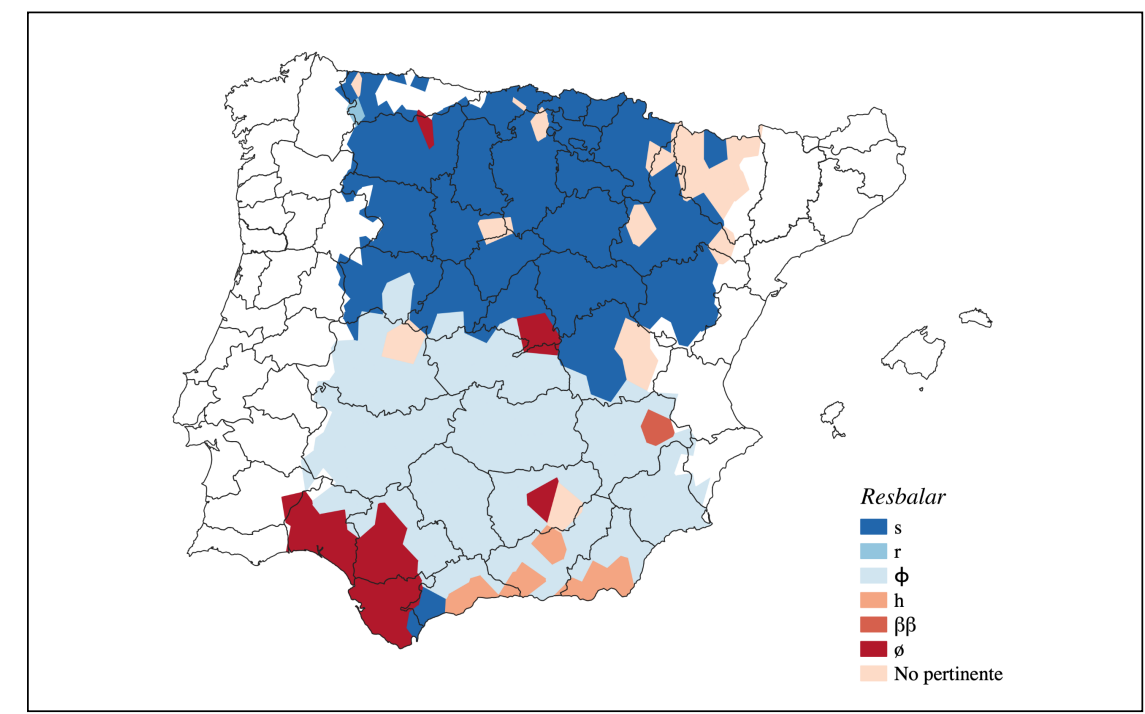

Mapa 3. -/s/ seguida de /b/: resbalar.

También es interesante el comportamiento de la sibilante ante la oclusiva dental sorda /t/. Como vemos en el Mapa 4, el debilitamiento de -/s/ alcanza una extensión ligeramente menor que en los contextos fonéticos anteriores $y$, de hecho, es el contexto fonético en posición interior que más favorece la pronunciación plena de -/s/. Es significativo que la sibilante se mantiene en algunos enclaves de la provincia de Cáceres (Ceclavín y Aliseda) y en un enclave de Murcia (Las Palas), pues son zonas en las que el fenómeno ha avanzado rápidamente, como veremos en otros contextos. Además, es especialmente relevante la conservación en el caso de Castilla-La Mancha oriental, donde se documenta -/s/ en el norte y este de Toledo, en la totalidad de Cuenca y en el oriente de Ciudad Real y de Albacete. Esta extensión del mantenimiento de /s/ en coda se debe sin duda al contexto fonético en el que se sitúa, pues / $t$ / es el sonido que menos incidencia tiene en el proceso de aspiración y pérdida. 


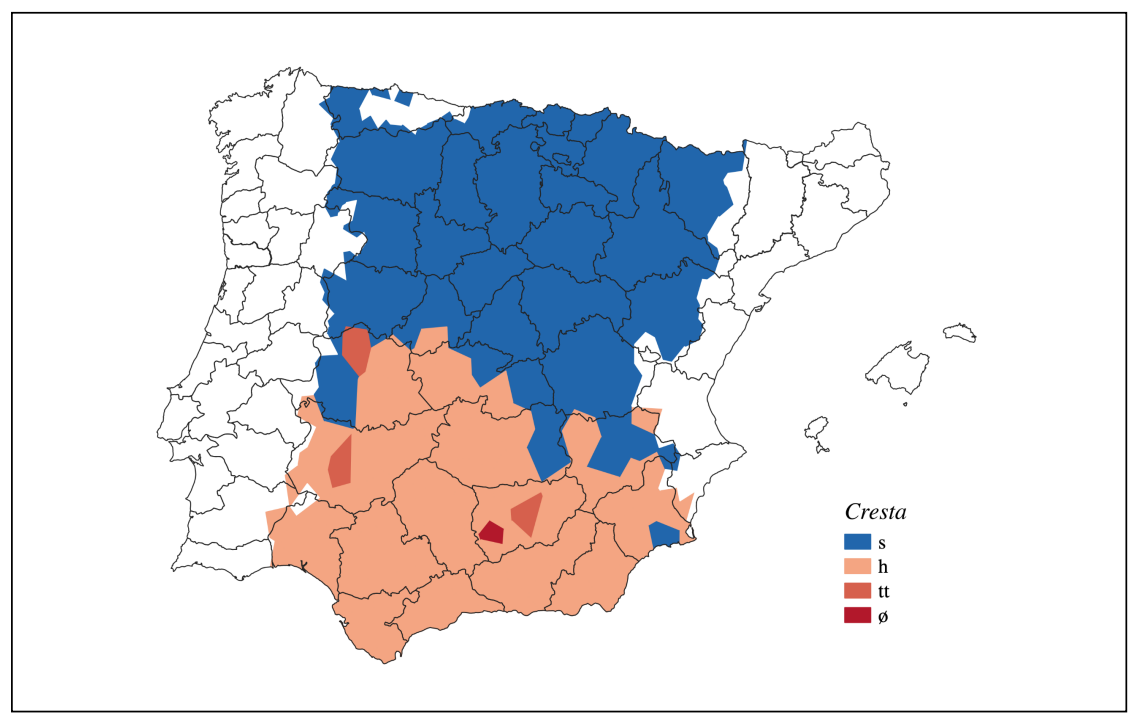

Mapa 4. -/s/ seguida de /t/: cresta.

El Mapa 5 muestra los resultados de la pregunta escopeta. La aspiración es incipiente en Ávila, donde solo dos enclaves preservan la -/s/ (La Horcajada y Las Navas del Marqués). También hay dos enclaves en Albacete que conservan la sibilante (Higueruela y Peñas de San Pedro), así como toda la provincia de Cuenca.

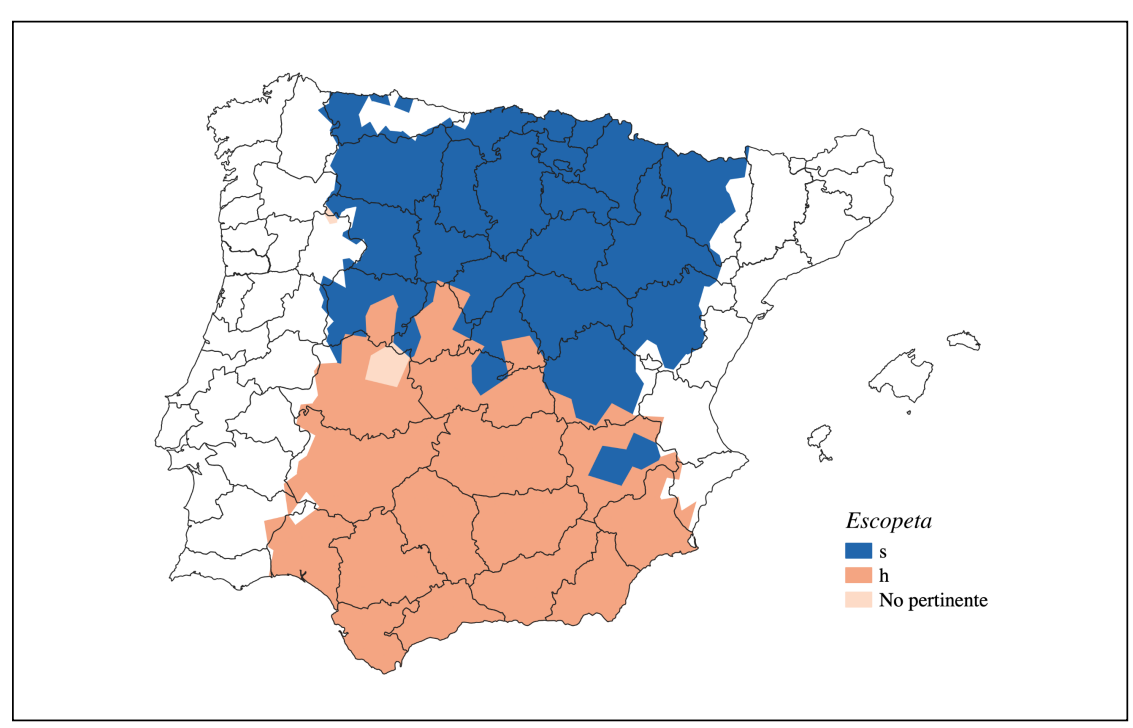

Mapa 5. -/s/ seguida de /k/: escopeta.

Algo menor es la extensión de la aspiración en el occidente en el Mapa 6, que proyecta los datos de la pregunta avispa. En este mapa son destacables, por un lado, los casos de geminación de la oclusiva bilabial en Jaén (Torre del Campo), Sevilla 
(Saucejo) y Cádiz (Chiclana); y, por otro, los casos de ensordecimiento localizados en las zonas que lindan con la conservación de -/s/ en Madrid (Cadalso de los Vidrios), Albacete (Caudete) y Murcia (Fuente del Pino).

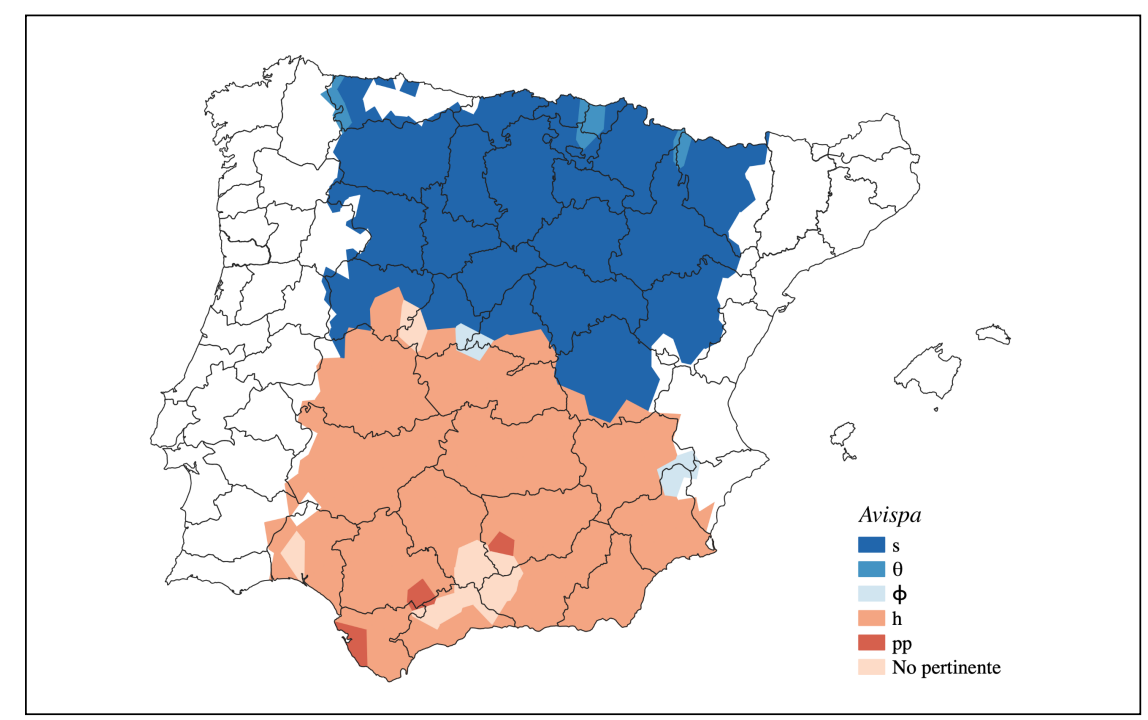

Mapa 6. -/s/ seguida de /p/: avispa.

Como podemos observar, los mapas de las preguntas escopeta (Mapa 5) y avispa (Mapa 6) presentan resultados similares a los de la pregunta desnudo (Mapa 2) en cuanto a la extensión geográfica del fenómeno. Sin embargo, las oclusivas sordas /k/ y $/ \mathrm{p} /$ son, al contrario que $/ \mathrm{n} /$, dos de los sonidos que menos favorecen el proceso de debilitamiento de $-/ \mathrm{s} /$, por lo que esperaríamos unos resultados más próximos a los advertidos en cresta (Mapa 4).

Por otro lado, los resultados del ALPI muestran que la geminación se produce especialmente con la lateral alveolar (Mapa 7), mientras que son casos aislados los que la documentan con oclusiva nasal (Mapa 8). 


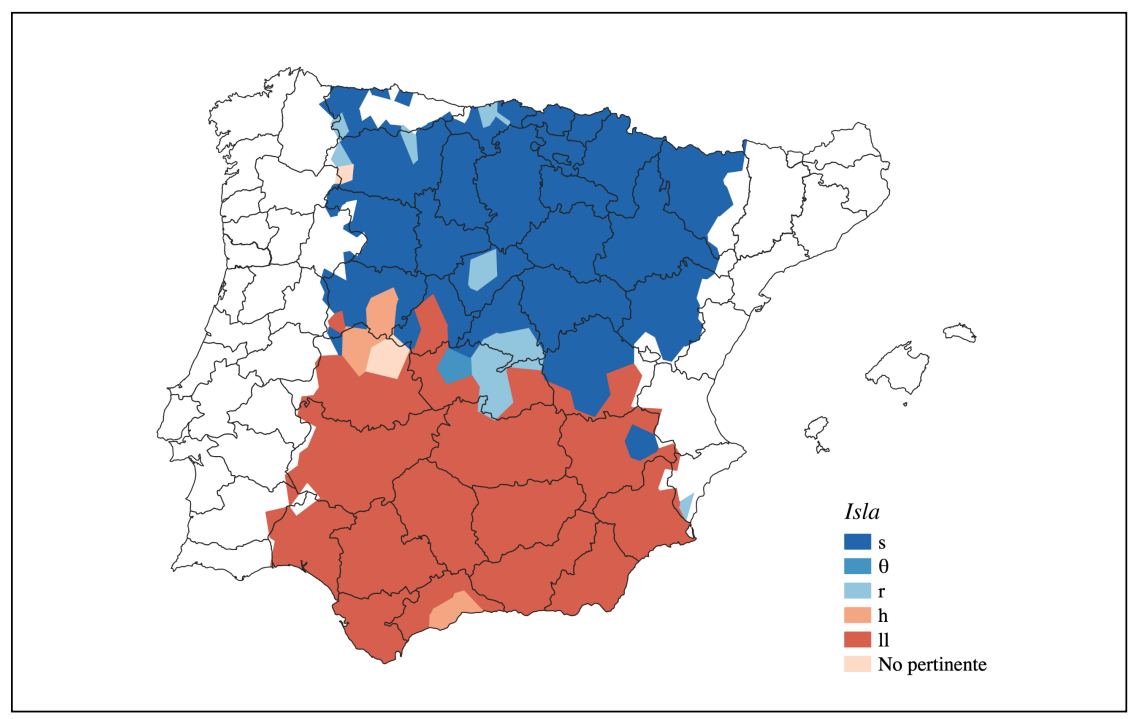

Mapa 7. -/s/ seguida de /I/: isla.

El bajo porcentaje de geminación en mismo es sorprendente si atendemos a otros estudios fonéticos (cfr. Fernández-Sevilla 1980, Martín Butragueño 1995, Molina Martos 1998, Martínez-Gil 2012), que suelen coincidir en que /m/ es uno de los sonidos que más casos presenta de geminación en el proceso de glotalización. En este caso, habría que observar las consonantes voladas dobles que se representan en los cuadernos del $A L P I$ y de las que solo se ha transcrito el primer elemento, habitualmente /h/, en la edición digital. Tal vez los mapas resultantes podrían variar si tuviéramos en cuenta esos sonidos relajados.

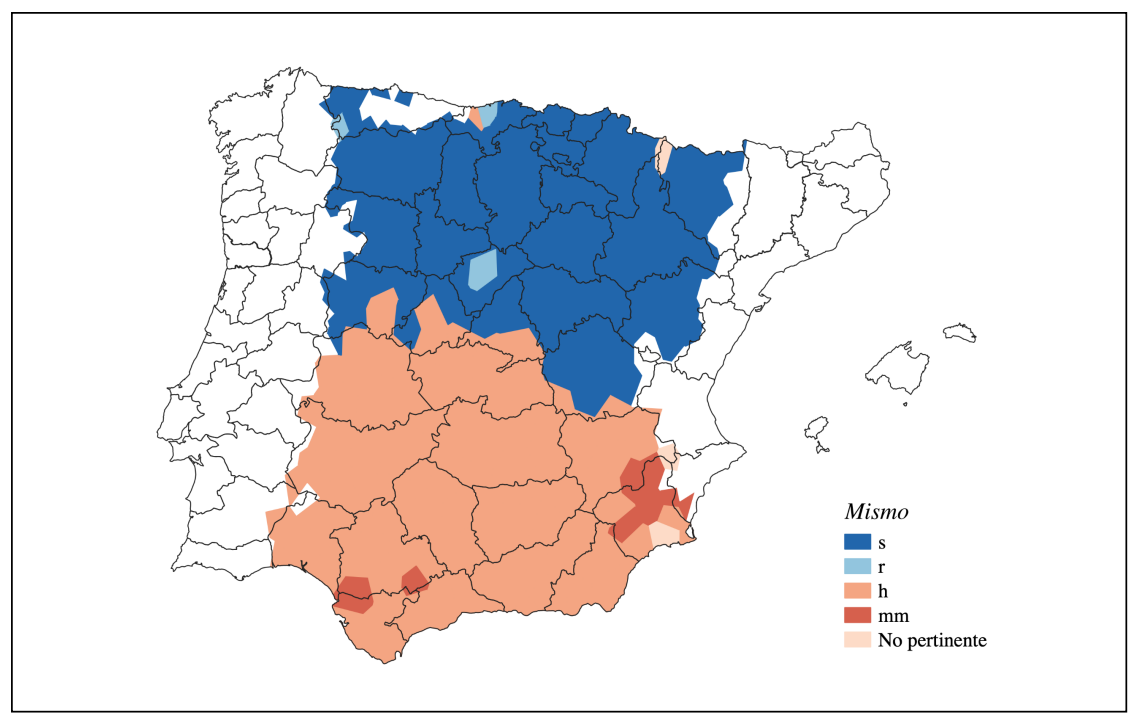

Mapa 8. -/s/ seguida de /m/: mismo. 
En suma, los mapas de -/s/ en posición interior nos muestran datos reveladores acerca de este cambio fonético. La lenición de la sibilante es mayoritaria en todo el territorio del español meridional y, de hecho, los resultados de los mapas muestran que el fenómeno ha alcanzado los mismos territorios en casi todos los contextos fonéticos, salvo en el caso de /t/, contexto en el que el proceso está algo más atrasado. Sin embargo, es evidente que en unas zonas el proceso diacrónico ha alcanzado diferentes grados de evolución. En Andalucía, Murcia y Extremadura el proceso es más o menos estable porque estas comunidades se encuentran en etapas más avanzadas del cambio. Por el contrario, los resultados inestables de Castilla-La Mancha, especialmente en Cuenca, y en el sur de Salamanca, Ávila y Madrid indican que el cambio se encuentra en etapas intermedias en estos territorios.

Además, el sonido consonántico que sigue a $-/ \mathrm{s} /$ modifica los resultados de la glotalización. La fase de aspiración predomina en el sur peninsular en todos los ejemplos analizados - desnudo, escopeta, avispa, mismo, desde y cresta-, excepto en resbalar, en que destaca el ensordecimiento, y en isla, en el que la geminación es mayoritaria. ${ }^{6}$

\section{$2.3-/ s /$ en el margen entre palabras}

El margen entre palabras es, según los estudios previos, la posición en la que se origina el cambio fonético de /s/ en coda silábica. En la Figura 1, podemos observar las diferencias geográficas de los resultados de la sibilante seguida de /p/ en distintos contextos sintácticos. Los casos de pérdida de $-/ \mathrm{s} /$ son la característica más relevante

\footnotetext{
${ }^{6}$ Hemos descartado la pregunta rasgar para el análisis dado que la forma general en toda la mitad meridional de la Península es rajar, cuya procedencia etimológica es distinta a la de rasgar (DCECH, s.v. rajar y s.v. rasgar). Además, las escasas localidades en que $-/ \mathrm{s} /$ se pierde ante $/ \mathrm{g} /$ en Las huertas (cfr. Mapa 9) nos llevan a pensar que tal vez no se trate de un caso de ensordecimiento como el que se produce en resbalar > refalar. Sin embargo, es curioso que la extensión geográfica de la voz rajar coincida en gran parte con la isoglosa del debilitamiento de $-/ \mathrm{s} /$, por lo que sería interesante analizar con más detenimiento este caso. También hemos descartado la pregunta desde, pues muchos de los resultados mantienen una nasal alveolar etimológica ( $\angle D E I N D E)$. En los enclaves que presentan la forma desde, es habitual el rotacismo de $-/ \mathrm{s} / \mathrm{y}$, en algunos puntos del sur meridional, documentamos una interdental sorda $/ \theta /$ (cfr. Figura 3 ).
} 
de estos mapas en tanto que permiten distinguir la evolución del fenómeno en unos y otros contextos. Como vemos, el mapa con los resultados del ejemplo Lo queréis para vosotros es el que presenta más casos de ausencia de la sibilante y a este le sigue el mapa Sois parientes, en que observamos cómo la pérdida total se encuentra de manera ocasional. En ambos mapas, los ejemplos de pérdida se localizan en Sevilla, Cáceres y Murcia. Finalmente, en el mapa Los pastores solo documentamos dos realizaciones, el mantenimiento de $-/ \mathrm{s} /$ o la aspiración, y ya no hay enclaves donde se pierde $-/ \mathrm{s} /$.

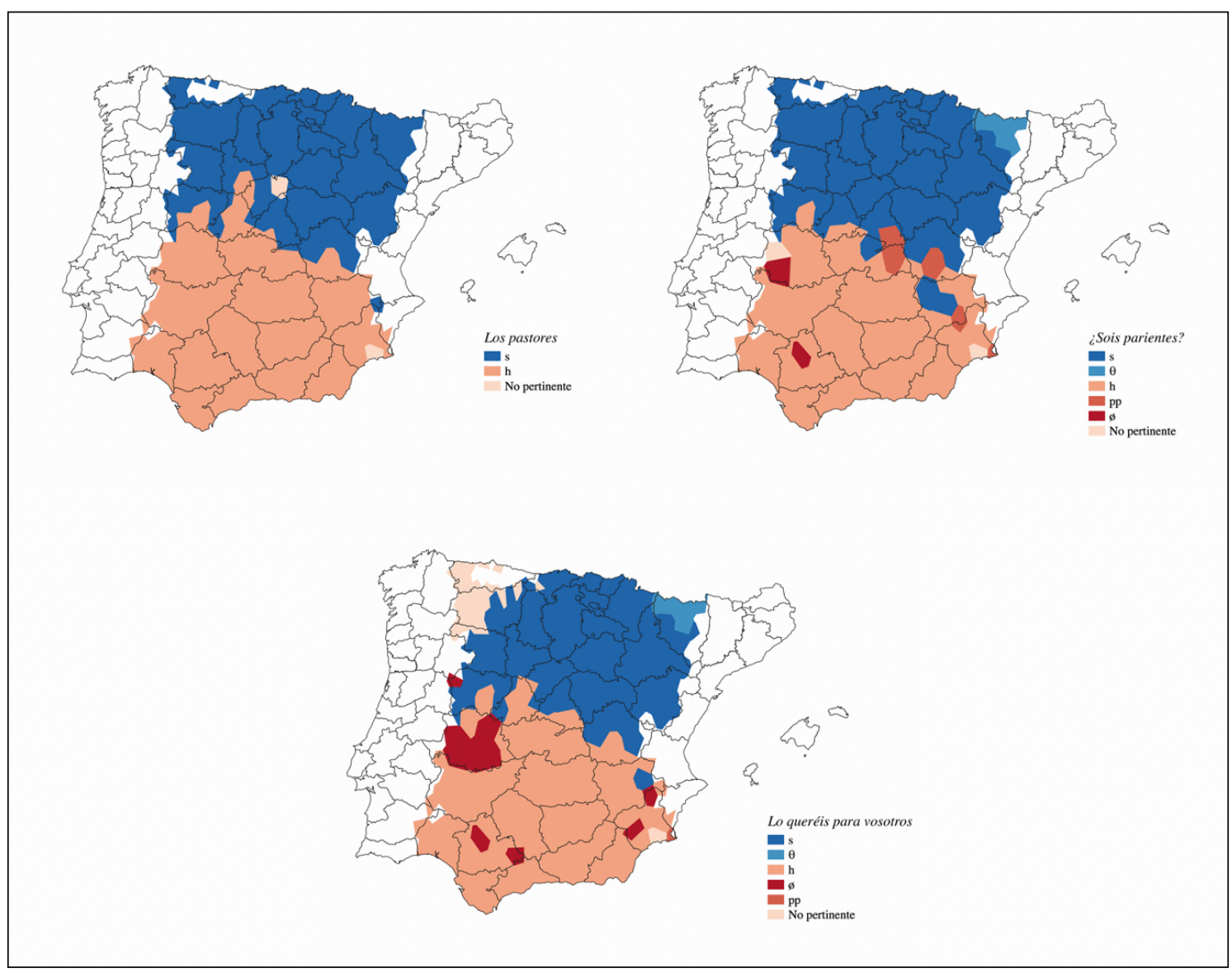

Figura 1. -/s/ seguida de /p/ en distintos contextos sintácticos.

En Los pastores, además, sobresale el alcance de la aspiración, que penetra en la provincia de Valladolid (Pedrajas de San Esteban). En esta respuesta, el encuestador anota que el informante vacila entre aspiración y mantenimiento, tanto en la sibilante del artículo los como en la interior de pastores. Este ejemplo, aunque evidencia que el cambio fonético es gradual e inestable en las zonas fronterizas a la isoglosa que divide 
en norte y sur la Península, hay que tomarlo con cautela ya que podría tratarse de un caso aislado de aspiración. De hecho, no hemos documentado en este enclave ningún otro caso de aspiración en los ejemplos seleccionados y /s/ en coda solo se debilita ante $/ d / y / r /$, que son los dos sonidos con más incidencia en este cambio fonético.

En la Figura 2 se representa la evolución de la -/s/ seguida de /k/ entre palabras. Los mapas también reflejan ciertos contrastes en los resultados de la sibilante, similares a los descritos en el contexto fonético de /p/. Entre estos ejemplos, destaca el mapa de Cada mes cambia. Este muestra varios casos de pérdida de -/s/ localizados en parte de la provincia de Sevilla, en un enclave de Cádiz y en el norte de Cáceres, pero lo más destacable es el mantenimiento en gran parte de la provincia de Albacete. Ello se debe a que Cada mes, como adjunto temporal, tiene menor unión sintáctica con el verbo que el posesivo con el nombre o el adverbio con la conjunción. En definitiva, en esos enclaves la $-/ \mathrm{s} /$ de mes puede haberse considerado prepausal. En Tenemos cada uno la pérdida se documenta en la provincia de Sevilla y en el occidente de Cáceres, y en Antes que amanezca solo se localiza la pérdida en Cáceres. Por último, en Mis cuñados no se documentan casos de elisión de la sibilante y la conservación de -/s/ retrocede hasta la provincia de Cuenca. 


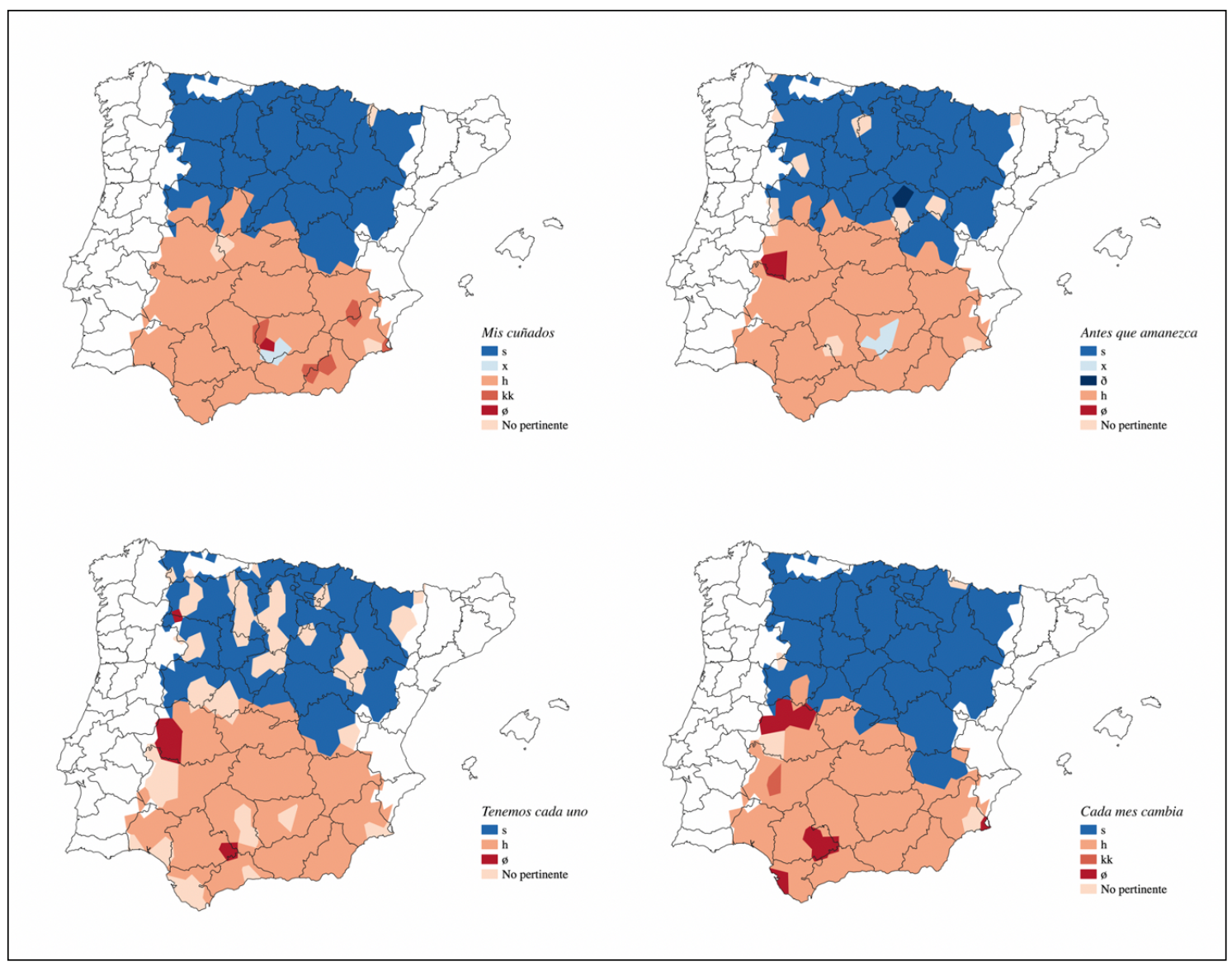

Figura 2. -/s/ seguida de /k/ en distintos contextos sintácticos.

Pero en otra pregunta con artículo + sustantivo, en Las huertas (Mapa 9), el debilitamiento de la sibilante parece encontrarse en estados más avanzados que en las otras preguntas del mismo contexto sintáctico vistas hasta ahora, Los pastores y Mis cuñados. Así, a pesar de que la fase de aspiración también es mayoritaria en todo el territorio meridional y son pocos los casos de geminación (de [ $\mathrm{\gamma}]$ en Caudete, Albacete, y de $[\beta]$ en Cadalso de los Vidrios, Madrid) o de ensordecimiento (Cebolla, Puebla de Don Rodrigo, La Puerta de Segura y Fuente del Pino), documentamos casos de pérdida de -/s/ en Cáceres, Murcia y Albacete. Estas diferencias surgen de forma clara por el contexto fonético en el que se encuentra la sibilante, ya que, según la escala de sonidos que inciden en el proceso, la velar sonora favorece más el debilitamiento de /s/ que las oclusivas sordas /p/o / k/. 


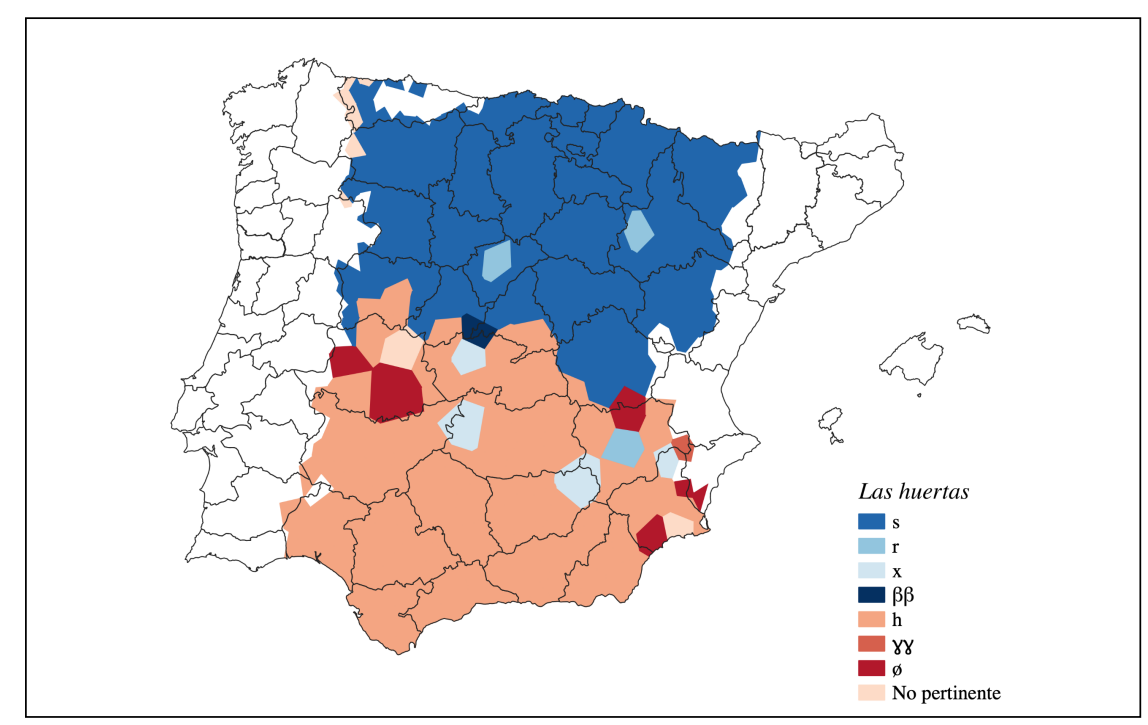

Mapa 9. -/s/ seguida de /g/: Las huertas.

Bien distintos son los mapas de la Figura 3 donde -/s/ va seguida de /d/. En Los domingos y ¿Cuándo salís de viaje? el rotacismo y el ensordecimiento son los resultados comunes. En estos ejemplos el debilitamiento alcanza enclaves del español septentrional en los que no se documenta el proceso de aspiración y pérdida en ningún otro contexto, excepto ante vibrante múltiple. Es muy interesante que la debilitación de -/s/ sea más intensa cuando forma parte del artículo seguida de un nombre que cuando forma parte del verbo seguida de un adjunto circunstancial, porque, de nuevo, en este segundo caso la unión sintáctica es menor. De hecho, la posición entre palabras sintácticamente unidas y ante /r/, como en Los reyes (Mapa 10), es la que más impacto tiene en el proceso de pérdida de la sibilante, pues incluso en la mitad septentrional de la Península -/s/ se asimila a la vibrante o se pierde por completo. 


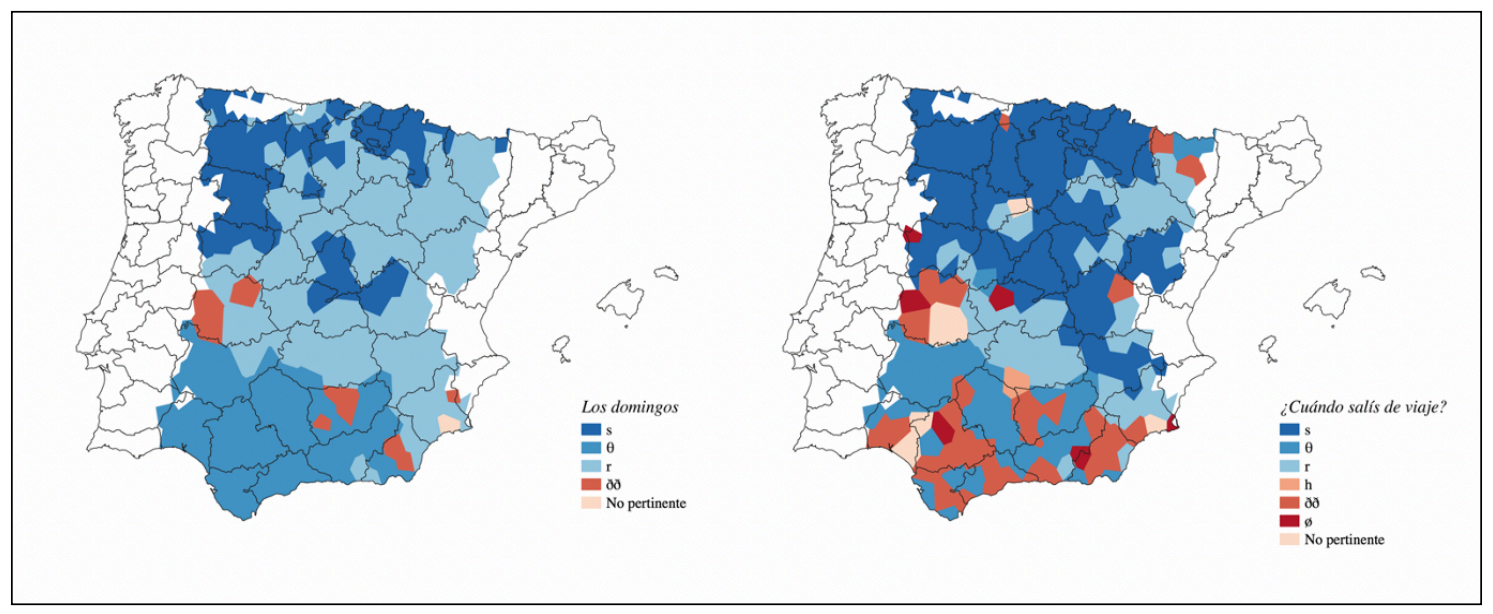

Figura 3. -/s/ seguida de /d/ en distintos contextos sintácticos.

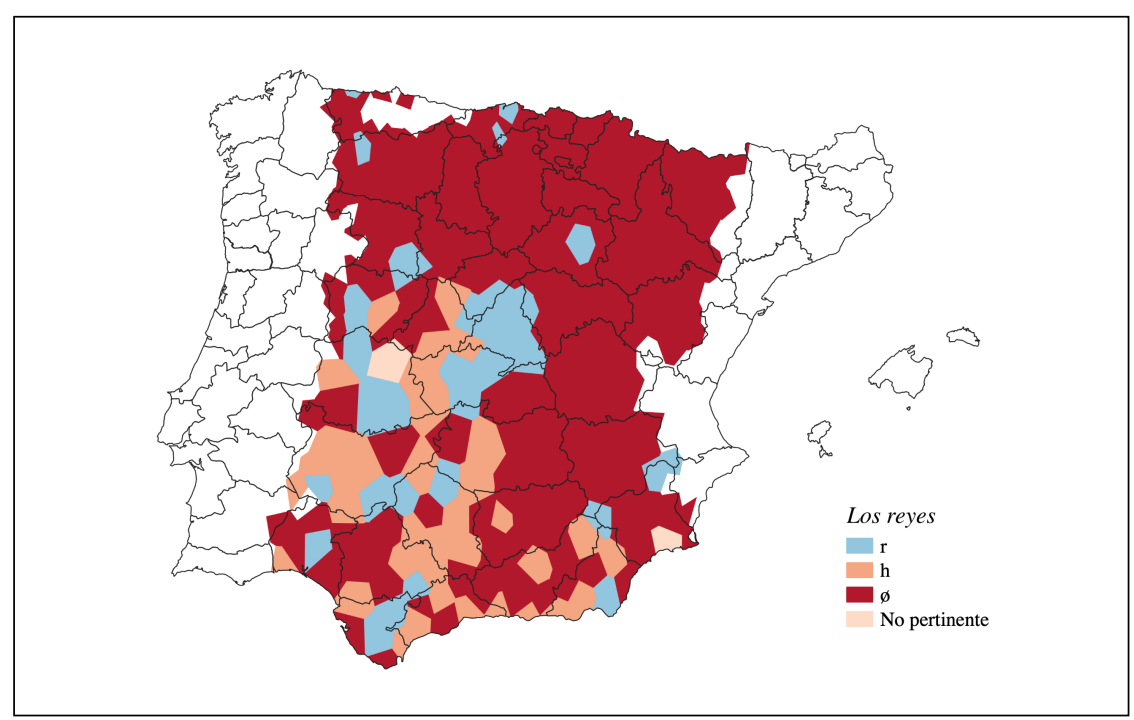

Mapa 10. -/s/ seguida de /r/: Los reyes.

Los mapas presentados en las Figuras 1, 2 y 3 proporcionan resultados interesantes en cuanto a la influencia del contexto sintáctico en el proceso de debilitamiento de -/s/. En estos ejemplos cabría esperar que -/s/ se comportase como interior a mayor unidad sintáctica y como prepausal a menor relación sintáctica, como de hecho sucede de forma sutil. Por un lado, los mapas de la Figura 2 descubren que el alcance geográfico del fenómeno de debilitamiento es distinto en unos y otros ejemplos, siendo mayor en mis+cuñados, antes+que y tenemos+cada que en mes+cambia. Las diferencias principales se concentran de nuevo en las zonas en las que el cambio fonético está en etapas intermedias, es decir, el sur de Salamanca, de Ávila y de Madrid y en Castilla-La Mancha, especialmente en Cuenca y Albacete. En la 
Figura 1, además, la aspiración solo alcanza el sur de Valladolid en Los pastores, mientras que hay ejemplos en que la /s/ se trata como final en queréistpara y sois+parientes.

Los mapas también reflejan fases diferentes del proceso. En la Figura 3 se ve que el rotacismo ha sido previo a la glotalización, ya que esta no aparece en Los domingos, mientras que en ¿Cuándo salís de viaje? los casos de geminación son más abundantes en toda la mitad meridional. Esta diferencia también puede deberse a la fonética sintáctica, por lo que -/s/ actúa como prepausal en el segundo ejemplo, con verbo + complemento, por encontrarse en un estado más avanzado del proceso, y como interior en el primero, con artículo + sustantivo, reflejando el estado previo.

No obstante, debemos tener en cuenta que no sucede lo mismo en otros contextos fonético-sintácticos. Por ejemplo, apenas hay casos de pérdida de la sibilante en el margen entre palabras cuando -/s/ va seguida de /b/ (Figura 4). Así, es Resbalar (Mapa 3) el que presenta más lugares con cero fonético, seguido de Las botellas, mapa en el que solo se pierde -/s/ en una reducida zona de Cáceres. En cambio, en Has barrido y Nos verá no se documentan casos de elisión. Es cierto, sin embargo, que los elementos que componen estos últimos ejemplos, auxiliar + participio y clítico + verbo, mantienen también una estrecha unión sintáctica, como las preguntas formadas por artículo + sustantivo, por lo que se diferencian de otros contextos sintácticos cuya relación sintáctica es menor, como los recogidos en las Figuras 1, 2 y 3. 


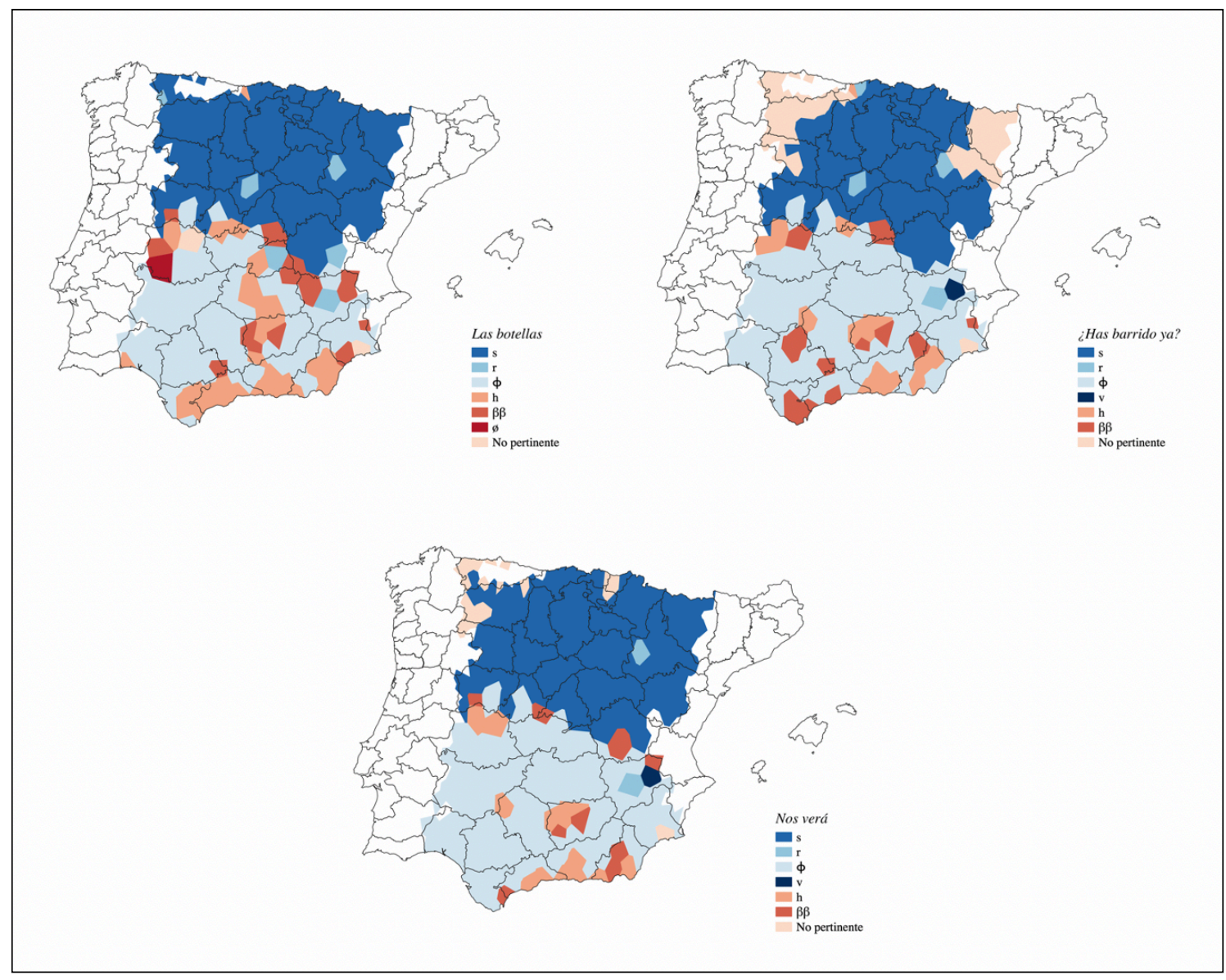

Figura 4. -/s/ seguida de /b/ en distintos contextos sintácticos.

También son relevantes los ejemplos en que $-/ \mathrm{s} /$ antecede a la palatal lateral $[\Lambda]$ o la aproximante palatal [j], como en ¿Has llegado? o Las yemas (Figura 5). En estos casos, la distribución de los resultados es muy dispar, ya que en el primer ejemplo la aspiración alcanza la provincia de Segovia (Barbolla) y, en el segundo, por el contrario, el mantenimiento de la sibilante se documenta en el occidente de Cáceres, en toda la franja oriental de Extremadura hasta penetrar en Córdoba, y en algunas localidades aisladas de Jaén y Almería. Sin embargo, a pesar de que el debilitamiento presenta un alcance geográfico menor, solo en Las yemas encontramos casos de pérdida de -/s/, localizadas en el norte de Cáceres (Pinofranqueado) y en Murcia (Pinilla, Ricote y Abanilla). En ambos ejemplos, además, se documentan casos de debilitación en Cantabria (Valle de Cabuérniga, Yermo y Espinama).

Asimismo, debemos tener en cuenta que en las zonas meridionales donde se produce el yeísmo las dos preguntas que se recogen en la Figura 5 pueden estar 
Dialectologia. Special issue, IX (2021), 311-339.

reproduciendo el mismo contexto fonético, lo que acentúa las diferencias entre uno y otro mapa.

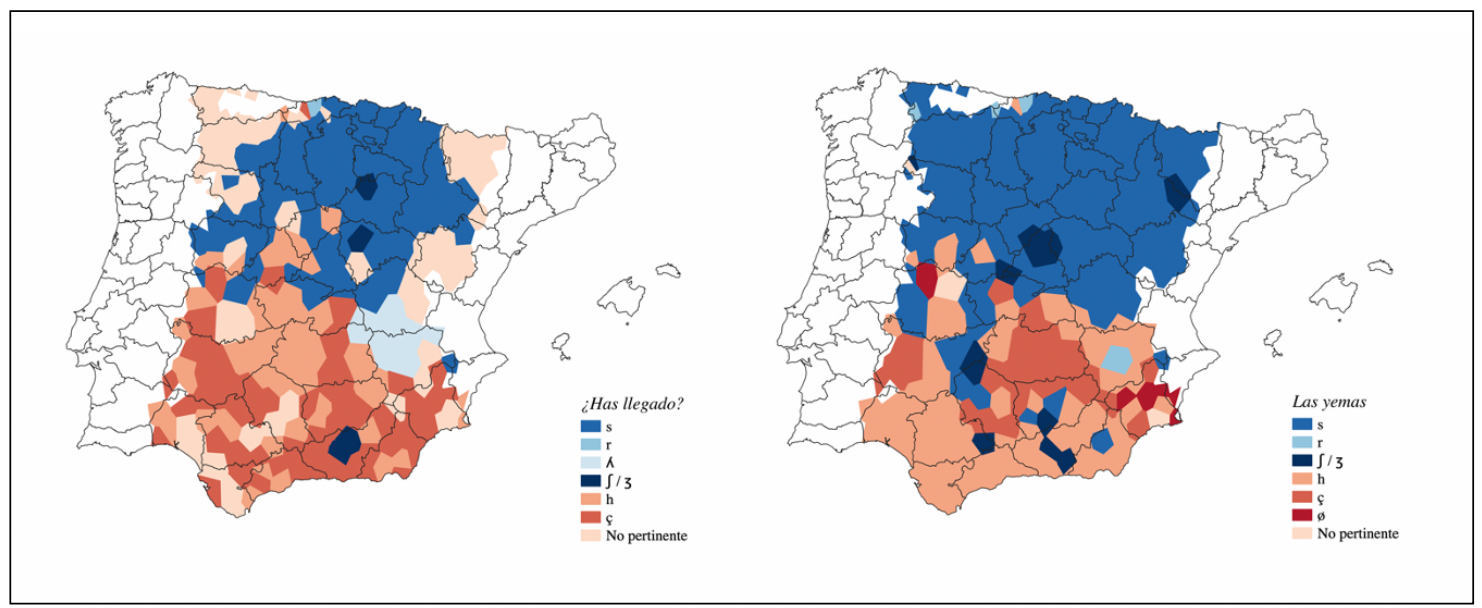

Figura $5 .-/ \mathrm{s} /$ seguida de $/ \mathrm{N} / \mathrm{o} / \mathrm{d} /$ en distintos contextos sintácticos.

Por su parte, si cotejamos los resultados de la pregunta Lo primero es la salud (Mapa 11) con los resultados de isla (Mapa 7), podemos observar que cuando -/s/ se sitúa en el margen entre palabras, los casos de geminación disminuyen respecto al contexto de posición interior, pero encontramos casos de elisión de la sibilante, localizadas de nuevo en Cáceres, Murcia y Cádiz, que no se documentan en isla.

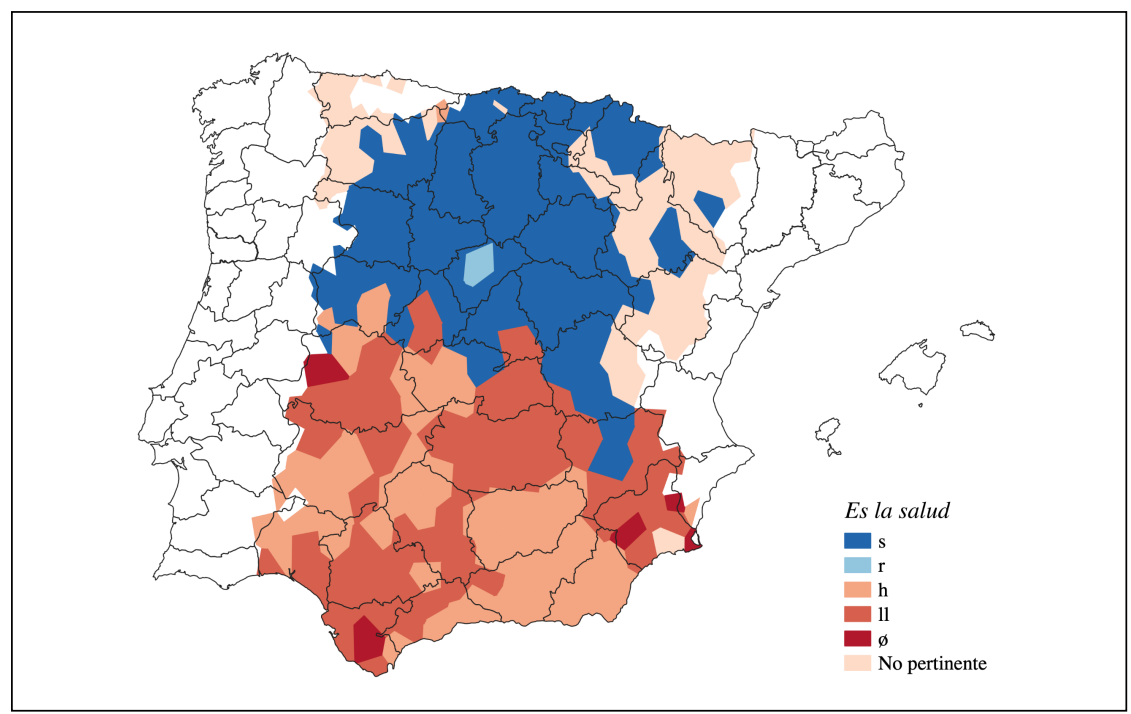

Mapa 11. -/s/ seguida de /I/: Es la salud. 
Por tanto, a pesar de que afloran algunos casos en los que este proceso diacrónico se encuentra más avanzado en aquellos ejemplos en los que la relación sintáctica entre los elementos que los componen parece ser menor, consideramos que los contrastes reflejados son mínimos para considerarlos significativos. La pérdida de la sibilante en el margen entre palabras no sigue un patrón geográfico concreto en nuestros mapas, aunque se produce con más frecuencia en enclaves de Sevilla, de Cáceres y de Murcia, zonas que coinciden con las áreas más avanzadas en el proceso señaladas por Catalán (1971). Este panorama puede ser el resultado de que el proceso se encuentra en marcha en esta posición y solo se observan esporádicas elisiones de la sibilante en los contextos fonético-sintácticos y en las zonas geográficas que más favorecen el cambio. Pero tampoco podemos descartar que estas pérdidas aisladas de -/s/ procedan del propio idiolecto de los informantes.

\section{$2.4-/ s /$ prevocálica}

La posición prevocálica es la última en verse afectada por el proceso de aspiración y pérdida de la sibilante. Así lo muestran también los mapas que presentamos de este contexto fonético. En el Mapa 12, podemos observar que la extensión del mantenimiento de la sibilante es más amplia que en la posición interior o en el margen entre palabras. De hecho, las zonas que conservan $-/ \mathrm{s} /$ son similares a las zonas que lo hacen en posición final absoluta (cfr. Mapa 1).

El debilitamiento de -/s/ en coda se registra en Andalucía, Murcia, Extremadura y el occidente de Castilla-La Mancha. Es interesante comparar este resultado, que refleja que Toledo y Ciudad Real conservan la consonante ante vocal, con el que tiene lugar cuando va seguida de consonante, en que se debilita en esas provincias. Además, es destacable que son numerosos los enclaves en los que se pierde la sibilante. Estas localidades, salvo algunos casos dispersos, se concentran, por un lado, en Sevilla y las zonas contiguas y, por otro, en Murcia y Almería. De nuevo, como en otros contextos, estas son las zonas donde el fenómeno se encuentra en una fase más avanzada. 


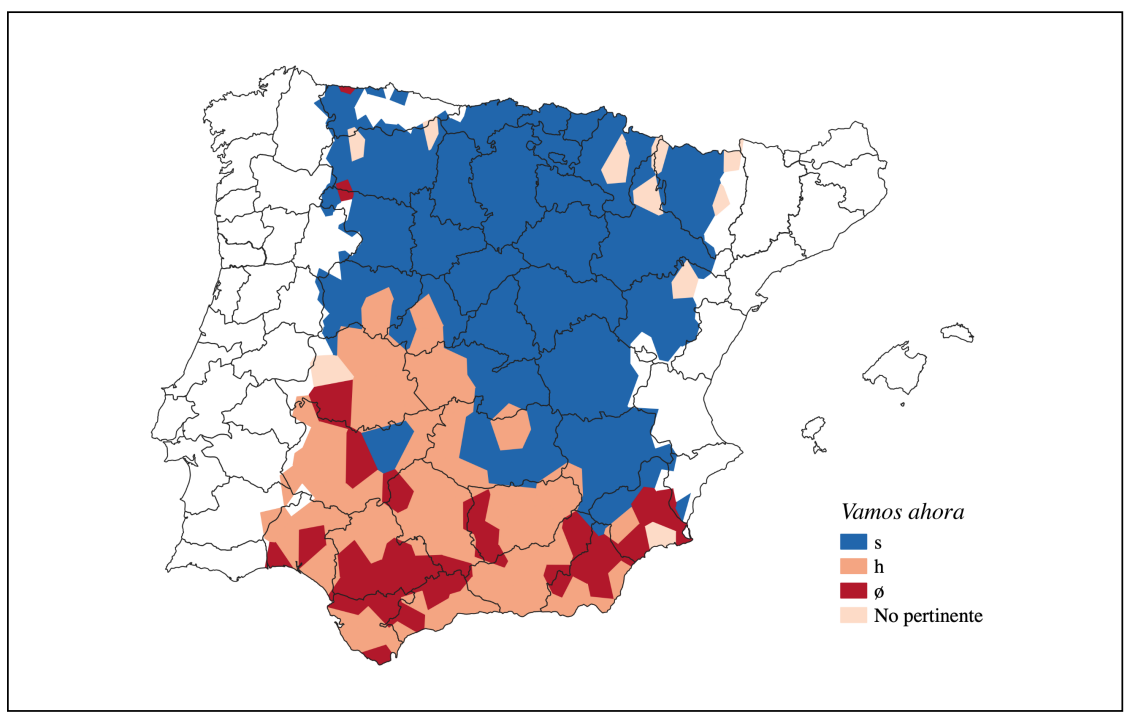

Mapa 12. - /s/ prevocálica en verbo + complemento. ${ }^{7}$

El Mapa 13 proyecta los datos de otro ejemplo en el que la sibilante se encuentra en posición prevocálica, Las hermanas, y las zonas en las que se documenta el mantenimiento de la sibilante son muy semejantes al Mapa 12. Lo que difiere en este caso son los casos aislados de pérdida, mucho más reducidos que en el ejemplo Vamos ahora y que se concentran exclusivamente en Murcia y el oriente de Andalucía.

\footnotetext{
${ }^{7}$ Son muy similares a este mapa las proyecciones resultantes de los ejemplos Fuimos a la feria, Tú y yo somos amigos y Os han engañado. Los ejemplos Me pidieron que les ayudase y Tráete los candiles para echarles aceite muestran otro fenómeno lingüístico, el uso del pronombre le singular para referente plural, por lo que hemos decidido no incluir los mapas en nuestro estudio. De la misma forma, tampoco mostramos el mapa del ejemplo Entonces escampó porque en muchas ocasiones se elide la sílaba repetida y no es posible determinar con exactitud si la aspiración o pérdida afecta a la sibilante en posición final agrupada o en posición interior.
} 


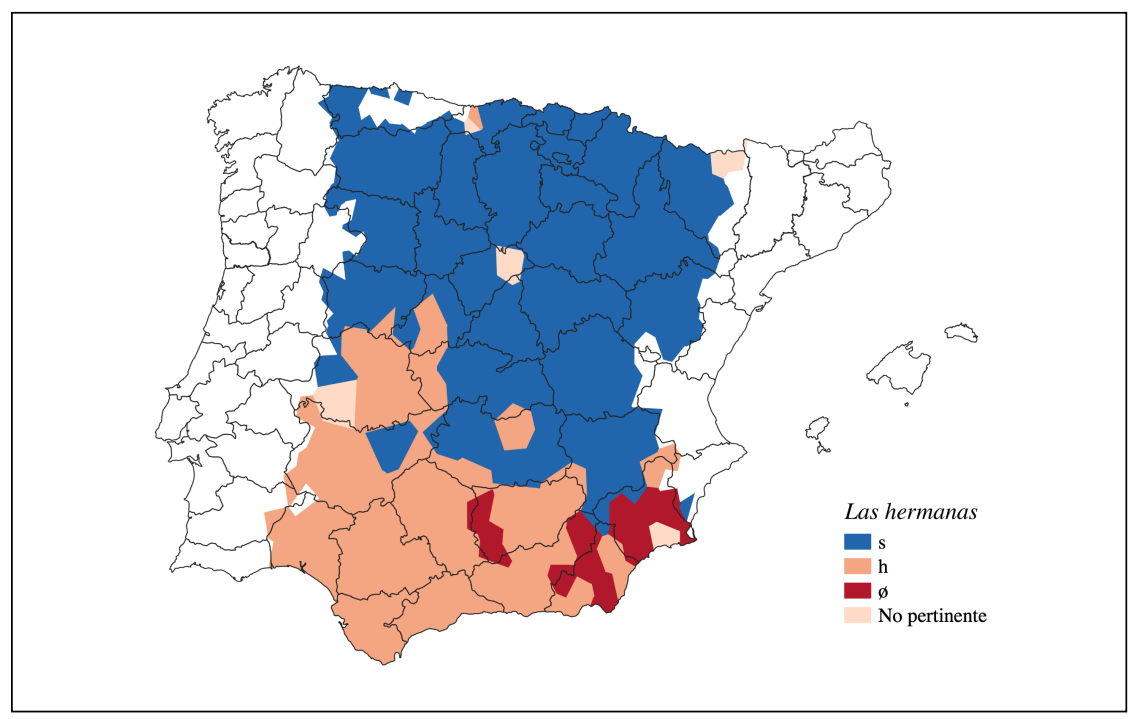

Mapa 13. -/s/ prevocálica en artículo + sustantivo.

Como hemos visto, en estos dos mapas de $-/ \mathrm{s} /$ en posición prevocálica, la extensión del fenómeno de debilitamiento se registra prácticamente en las mismas zonas. La diferencia entre ambos mapas surge del diferente contexto sintáctico de los ejemplos. En el Mapa 12, el proceso de pérdida de la sibilante se encuentra ligeramente más avanzado que en el Mapa 13. Así, ante el contexto verbo + complemento, Vamos ahora, la sibilante parece comportarse más como -/s/ prepausal, lo que favorece la pérdida total en las zonas donde el cambio fonético está más avanzado, a pesar de que no ha alcanzado la última etapa del proceso en todo el territorio meridional, como sucede en posición prepausal (cfr. Mapa 1). En cambio, en Las hermanas, el contexto sintáctico de artículo + sustantivo, en el que la relación entre los elementos que componen el sintagma se presupone más estrecha que en el caso anterior, refleja que el cambio está algo más atrasado.

Por tanto, el contexto sintáctico parece incidir ligeramente en el proceso evolutivo de /s/ en posición implosiva, al menos en contexto prevocálico, tal vez debido a que es el último contexto en verse afectado por el debilitamiento y, por tanto, a que se encuentra en una fase intermedia del proceso diacrónico. 


\section{Conclusiones}

En este trabajo hemos observado el comportamiento de $-/ \mathrm{s} /$ en los datos del $A L P I$. La imagen que nos ofrece este atlas del español en la primera mitad del siglo XX nos permite ver que la isoglosa del debilitamiento de /s/ en coda silábica no es la misma según la palabra considerada o el contexto fónico-sintáctico. Esta isoglosa varía según la posición que ocupa -/s/ en la cadena fónica -final absoluta, interior, margen entre palabras o prevocálica-, el contexto fonético -la consonante que sigue- $y$, en menor medida, el contexto sintáctico.

En los mapas presentados se observa la extensión geográfica del debilitamiento de /s/ en posición implosiva. El fenómeno se extiende prácticamente por toda la mitad meridional de la Península Ibérica, pero la evolución del cambio y las etapas iniciales del proceso pueden verse con más detalle en Castilla-La Mancha, especialmente en la provincia de Cuenca, y en las zonas limítrofes con el mantenimiento de -/s/ prepausal, de forma notoria en el sur de Salamanca, de Ávila y de Madrid. En estas provincias, donde rara vez se pierde la sibilante en esa posición, los datos reflejan, en cambio, el debilitamiento de -/s/ seguida de consonante. La debilitación ante vocal alcanza aun menor extensión geográfica, puesto que no se da en parte de Ciudad Real y Toledo, que sí glotalizan en los contextos anteriores. En Andalucía, Extremadura y Murcia el cambio fonético se encuentra en una fase muy avanzada, por lo que las etapas del proceso son, por lo general, poco perceptibles en los datos del ALPI.

En aquellas zonas donde el cambio está en etapas incipientes en los datos del $A L P I$ sería interesante observar la evolución del comportamiento de -/s/ hasta la actualidad. El estudio de Francisco Sánchez (2019) refleja que los rasgos meridionales del sur de la provincia de Salamanca se encuentran en retroceso probablemente por el prestigio de los rasgos septentrionales de la ciudad de Salamanca. Así, nos encontraríamos ante dos fenómenos opuestos en un mismo territorio: por un lado, la tendencia al debilitamiento de las consonantes finales en español, cuya evolución tiende a la pérdida por la preferencia de la estructura silábica CV (cfr. Catalán 1971); y, por otro, la presión de la norma escrita y de la variedad estándar, cuyo prestigio favorece el mantenimiento de las consonantes implosivas. 
Además, hemos mostrado las diferentes etapas evolutivas del proceso diacrónico de /s/ en coda silábica. Sin embargo, la edición digital del ALPI iguala en la transcripción los sonidos plenos y los sonidos relajados, por lo que en nuestros mapas no se observa con detalle la distinción realizada por Navarro Tomás (1975) de las zonas donde se conserva -/s/ plena y donde se documenta -/s/ reducida. En futuros estudios, cabría observar la diferencia entre esos estadios para determinar con mayor exactitud el alcance del debilitamiento de /s/ implosiva en la Península Ibérica.

Por otro lado, los datos revelan que no debemos confundir la extensión geográfica del fenómeno con la evolución de los distintos procesos evolutivos de /s/ en distensión silábica. Hemos comprobado que la posición final absoluta y la posición prevocálica son los dos contextos que menor alcance geográfico presentan, porque son los últimos en que -/s/ se debilita, y que, de ellas, la primera es la posición que más favorece la pérdida de la sibilante una vez que el cambio fonético ha comenzado. En cambio, el margen entre palabras y la posición interior seguidas de consonante parecen conservar los estadios iniciales del cambio (Méndez Dosuna 1987, Moreno Fernández 2004, Samper Padilla 2011, Fernández-Ordóñez 2016), pero son las que menos casos de pérdida registran.

Pero no solo la posición que ocupa la sibilante incide en el proceso, también el contexto fonético es un factor relevante en el cambio lingüístico de $-/ s />-/ \varnothing /$. Los resultados de la glotalización que hemos obtenido siguen la línea de los estudios previos (cfr. Martínez-Gil 2012, Fernández-Ordóñez 2016) y revelan que la vibrante múltiple /r/ y la dental sonora /d/ son los sonidos que más intervienen en el debilitamiento de la sibilante, $y$, en el otro extremo, la dental sorda / $t$ / es la que menos altera la pronunciación de $-/ \mathrm{s} /$.

Asimismo, hemos analizado la relevancia de la fonética sintáctica en el proceso de aspiración y pérdida de la sibilante. En términos generales, el contexto sintáctico no parece tener una incidencia determinante en el cambio fonético. No obstante, hay pequeñas diferencias en la extensión del fenómeno según el contexto fonéticosintáctico en el que se encuentra -/s/, sobre todo en las zonas de Castilla-La Mancha y el sur de Salamanca, Ávila y Madrid, y en la posición prevocálica, aunque también existen sutiles contrastes, pero poco significativos, en el margen entre palabras. Estas 
divergencias sugieren que los elementos que mantienen una relación sintáctica menos estrecha desde el punto de vista estructural tienden a tratar la $-/ \mathrm{s} /$ como prepausal, mientras que cuando la $-/ \mathrm{s} /$ se integra en una misma unidad sintagmática (como en artículo + nombre) tienden a tratarla como interior. En este sentido, ha resultado claro que el influjo del contexto sintáctico solo podemos documentarlo en los contextos y las posiciones en que el cambio se produce más tarde y, en consecuencia, en las zonas en las que el cambio se encuentra todavía en etapas intermedias.

\section{Referencias bibliográficas}

AlARCOS LLORACH, E. (2012 [1950]) Fonología española, Madrid: Gredos.

Alvar, M. (1996) Manual de dialectología hispánica. El español de España, Barcelona: Ariel.

ARIZA, M. (1999) "De la aspiración de -/s/", Philologia hispalensis, 13, 1, 49-60.

CANFIELD, D. L. (1981) Spanish Pronunciation in the Americas, Chicago: University Chicago Press.

CATALÁN, D. (1971) “En torno a la estructura silábica del español de ayer y del español de mañana", Sprache und Geschichte. Festschrift für Harri Meier, 77-110.

DCECH = COROMINAS, J. \& J. A. Pascual, (1980-1991) Diccionario crítico etimológico castellano e hispánico, Madrid: Gredos.

FERNÁNDEZ-ORdóÑEZ, I. (2016) "Dialectos del español peninsular", en Gutiérrez-Rexach, J. (ed.), Enciclopedia de Lingüística Hispánica, vol. 2, Londres \& New York: Routledge, 387-404.

FERNÁNDEZ-SEVILLA, J. (1980) "Los fonemas implosivos en español”, Thesaurus, XXXV, 3, 456-505. FRAGo GARCíA, J. A. (1983) "Materiales para la historia de la aspiración de la -/s/ implosiva en las hablas andaluzas", Lingüística Española Actual, vol. 5, 1, 153-171.

FRANCISco SÁNCHEZ, G. (2019) "Fonética y morfosintaxis del vernáculo de la Sierra de Francia (sur de Salamanca). Una aproximación histórica y sociolingüística", Dialectologia, 22, 3156.

García Mouton, P. (coord.), I. Fernández-Ordóñez, D. Heap, M. P. Perea, J. Saramago, X. Sousa (2016) ALPI-CSIC [en línea] <www.ALPI.csic.es>. Edición digital de Tomás Navarro Tomás (dir.), Atlas Lingüístico de la Península Ibérica, Madrid, CSIC.

GARCíA Mouton, P. \& F. Moreno Fernández (1994) “El Atlas Lingüístico y Etnográfico de CastillaLa Mancha. Materiales fonéticos de Ciudad Real y Toledo", en P. García Mouton, (ed.), Geolingüística. Trabajos europeos, Madrid: CSIC, 127-141. 
LAPESA, R. (1980) Historia de la lengua española, Madrid: Gredos.

LLEAL, C. (2004) “El judeoespañol”, en R. Cano (ed.), Historia de la lengua española, Barcelona: Ariel, 1139-1167.

Martín ButragueÑo, P. (1995) "La variable (s) en el sur de Madrid. Contribución al estudio de la frontera de las hablas meridionales del español", Anuario de Letras, 33, 5-57.

Martínez-GIL, F. (2012) “Main Phonological Processes”, en J. I. Hualde, A. Olarrea \& E. O’Rourke (eds.), The Handbook of Hispanic Linguistics, Malden/Oxford: Blackwell Publishing, 111131.

MÉndez DosunA, J. (1987) “La aspiración de s como proceso condicionado por el contacto de sílabas", Revista de la Sociedad Española de Lingüística, 17, 1, 15-35.

Molina MARTOS, I. (1998) La fonética de Toledo. Contexto geográfico y social, Alcalá de Henares: Universidad de Alcalá.

Molina MARTOS, I. (2015) "La variable sociolingüística -/s/ en el distrito de Vallecas (Madrid)", en A. M. Cestero Mancera, I. Molina Martos, F. Paredes García (coords.), Patrones sociolingüísticos de Madrid, Suiza: Peter Lang, 91-116.

Moreno FernÁNDEZ, F. (2004) “Cambios vivos en el plano fónico del español: variación dialectal y sociolingüística", en R. Cano (ed.), Historia de la lengua española, Barcelona: Ariel, 973-1010.

NAvArRo TomÁs, T. (1975) "Áreas geográficas de consonantes finales", Capítulos de geografía lingüística de la Península Ibérica, Bogotá: Instituto Caro y Cuervo, 175-199.

Paredes García, F. (2006) "Dialectología y sociolingüística en Madrid", en A. M. Cestero Mancera, I. Molina Martos, F. Paredes García (coords.), Estudios sociolingüísticos del español de España y América, Madrid: Arco Libros, 221-231.

PASCUAL, J. A. (1998) “El revolucionario conservadurismo del español norteño: a propósito de la evolución de la s implosiva", Estudios de lingüística y filología españolas: homenaje a Germán Colón, Madrid: Gredos, 387-400.

PENNY, R. (1978) Estudio estructural del habla de Tudanca, Tübingen: Niemeyer.

PENNY, R. (1991) "El origen asturleonés de algunos fenómenos andaluces y americanos", Lletres asturianes, 39, 33-40.

PENNY, R. (2000) Variación y cambio en español, Madrid: Gredos.

Pérez-MARtín, A. M. (2003) Estudio sociolingüístico de El Hierro, Las Palmas: Universidad de Las Palmas de Gran Canaria.

SalvadoR, G. (1987) Estudios dialectológicos, Madrid: Paraninfo. 
Dialectologia. Special issue, IX (2021), 311-339.

ISSN: 2013-2247

SAmper PAdilla, J. A. (2011) "Sociophonological Variation and Change in Spain", en M. DíazCampos (ed.), The Handbook of Hispanic Sociolinguistics, Malden/Oxford: Blackwell Publishing, 98-120.

SAmper PAdilla, J. A. \& C. Hernández-Cabrera (1995) “La variación de -/s/ en el español culto de Las Palmas de Gran Canaria", Philologica Canariensia, 2, 391-408.

SÁNCHEZ ROMO, R. (2011) “Análisis contrastivo del cambio lingüístico de la aspiración: el sur de Ávila y Extremadura", Anuario de estudios filológicos, 34, 219-236.

SÁNCHEZ ROMO, R. (2014) “Aproximación diacrónica a la aspiración de /s/ en las hablas meridionales, ¿nuevas huellas en la documentación medieval de Mombeltrán?", Dialectologia, 13, 49-70.

TORREBlANCA, M. (1989) "La /s/ implosiva en español: sobre las fechas de su aspiración", Thesaurus, XLIV, 2, 281-303.

VIDA, M. (2004) Estudio sociofonológico del español hablado en Málaga, Alicante: Universidad de Alicante.

ZAMORA VICENTE, A. (1967) Dialectología española, Madrid: Gredos. 